\title{
Microscopic Structure of the Epithelium Lining the Epiglottis in Wistar Rats
}

\author{
Vasile RUS ${ }^{1 *}$, Aura Ștefania PARDI ${ }^{1}$, Bianca MATOSZ ${ }^{1}$, Flavia RUXANDA ${ }^{1}$ \\ ${ }^{1}$ Faculty of Veterinary Medicine, USAMV Cluj-Napoca, Romania \\ corresponding author: vasile.rus@usamvcluj.ro
}

Bulletin UASVM Veterinary Medicine 75(1)/2018

Print ISSN 1843-5270; Electronic ISSN 1843-5378

doi:10.15835/buasvmcn-vm:000717

\begin{abstract}
The aim of this study was to investigate the type of the epithelium present on the epiglottis surface, through histological examination. The epithelium lining the pharyngeal side of epiglottis is keratinized stratified squamous. The thickness of the keratin layer is different from one subject to another. Usually the keratin layer extends to the apex of the epiglottis, but in some of the animals taken into study, the keratin layer extends to the apical third of the laryngeal side of epiglottis. The epithelium lining the laryngeal side is different. In most of the epiglottises examined, the surface is lined by non-keratinized stratified squamous epithelium in the apical third. The rest of the laryngeal side of the epiglottis is lined by respiratory epithelium type. In one subject, the entire laryngeal surface is lined by a non-keratinized stratified squamous epithelium. Our study highlights that the pharyngeal side of epiglottis is lined by a keratinized stratified squamous epithelium, whereas on the laryngeal side, the epithelium in the apical third is non-keratinized stratified squamous and at the rest of the surface the epithelium is pseudostratified.
\end{abstract}

Key words: epiglottis, epithelium, rat.

\section{Introduction}

The larynx is an important organ in many studies conducted on the effects of various substances used in pharmaceutical or chemical industry, agriculturalchemicals, and environmental pollutants. The histological structure of the rat larynx is also assessed in studies on the inhalation toxicity and carcinogenicity (Lewis, 1991).

The epiglottis has a central axis represented by elastic cartilage. Generally, in animals, the pharyngeal side of the epiglottis has a nonkeratinized stratified squamous epithelium (Raica et al., 2004), and the laryngeal side is lined a respiratory epithelium (Gal and Miclăuș, 2013). Some authors (Junqueira et al., 1992) affirm that the non-keratinized squamous stratified epithelium also continues on the laryngeal surface. In lambs, the whole surface of the epiglottis is covered by a non-keratinized squamous stratified epithelium (Rus et al., 2016).
In mice, the epithelium which covers the epiglottis was studied by Nakano and Muto (1987). In the caudal portion of the laryngeal side of the epiglottis, the epithelium is pseudostratified and towards pharynx the epithelium becomes nonkeratinized squamous stratified. These types of epitheliums were similarly with those described by Kahwa and Purton in goats (1996).

In rodents, the epithelium that covers the epiglottis was studied by Renne and Miller (1996). These authors describe a non-keratinized squamous stratified epithelium with few keratinized cells on the pharyngeal side and state that the epithelium becomes thinner toward the laryngeal one. This type of epithelium becomes a transitional epithelium with few ciliated cells; at the base of laryngeal side of the epiglottis, the epithelium becomes pseudostratified. Smith (1997) describes the epithelium lining the rat's larynx. The epiglottis is covered by a non- 
keratinized squamous stratified epithelium which becomes pseudostratified non ciliated at the base of laryngeal side, whereas towards the larynx cavity it becomes ciliated (with the exception of the vocal cords) (Smith, 1997). The aim of this study was to investigate the epithelium type on the epiglottis surface in Wistar rats, through histological examination.

\section{Materials and methods}

In this study we harvested longitudinal fragments of epiglottis from 5 healthy adults' male rats. The samples were fixed for 24 hours by immersion in Stieve solution, dehydrated in ethylic alcohol, clarified in n-butanol and embedded in paraffin. The samples were sectioned at $5 \mu \mathrm{m}$ and stained with Goldner's trichrome method.

\section{Results and discussions}

The epithelium which covers the epiglottis is not the same type on both sides (pharyngeal and laryngeal). On the pharyngeal side, the epithelium is keratinized stratified squamous (Fig. 1). In 4 out of 5 rats, the keratin layer is thinner and extends to the apex of the epiglottis (Fig. 2). In one rat, the keratin layer is ticker and extends to the apical third of laryngeal side of the epiglottis (Fig. 3). The basal membrane forms folds and the amplitude and the density of those folds depend on the thickness of the epithelium. At the base of the pharyngeal side, where the epithelium is thicker, the folds of the basal membrane are higher and have a high density. Toward the apex of the epiglottis, the epithelium becomes thinner and the amplitude and the density of the basal membrane folds become smaller. On the laryngeal side of the epiglottis, the lining epithelium is not the same on the whole surface. In the apical third of the laryngeal side of the epiglottis, in 4 out of 5 rats taken into study, the epithelium is non-keratinized stratified squamous (Fig. 4), whereas in one rat this epithelium is keratinized. In the basal half of the laryngeal side of the epiglottis, the epithelium is pseudostratified columnar with cilia (Fig. 5) and few goblet cells. Between these two areas there is a transitional epithelium with few ciliated columnar cells. In one rat, the entire laryngeal side of the epiglottis is cover by a non-keratinized stratified squamous epithelium (Fig. 6). Generally, the epithelium which covers the laryngeal side of the epiglottis is thinner than the one covering the pharyngeal side and the basal membrane does not form deep and dense folds; it is almost straight.

Our results contradict those presented by other authors, which affirm that the laryngeal side of the epiglottis is lined by a non-keratinized stratified squamous epithelium (Renne and Miller, 1996; Smith, 1997). Regarding the laryngeal side of the epiglottis our results are similar with those described by other authors, but not identical. We identified a non-keratinized stratified squamous epithelium only in the apical third of the laryngeal side of the epiglottis, while Rene and Miller (1996) and Smith (1997) affirm that this type of epithelium extends to the limit between middle and basal third of the laryngeal side. The opening of the minor salivary glands of the epiglottis is located on this side and from this point; the epithelium of the base of the epiglottis becomes pseudostratified with ciliated cells. In one rat taken into study, we found that the entire laryngeal side of the epiglottis was lined by a non-keratinized stratified squamous epithelium, even at the basal area of the epiglottis. Probably the epithelium which covered the basal third of laryngeal side of the epiglottis had a metaplastic transformation to squamous epithelium. It is known that the base of the epiglottis is the most sensitive region to squamous metaplasia in rodents and is recognized as a preferred site for histopathological evaluation in toxicology of some administered substances (Rene et al., 1992; Sagartz, 1992; Hayes, 2008; Sahota, 2013).

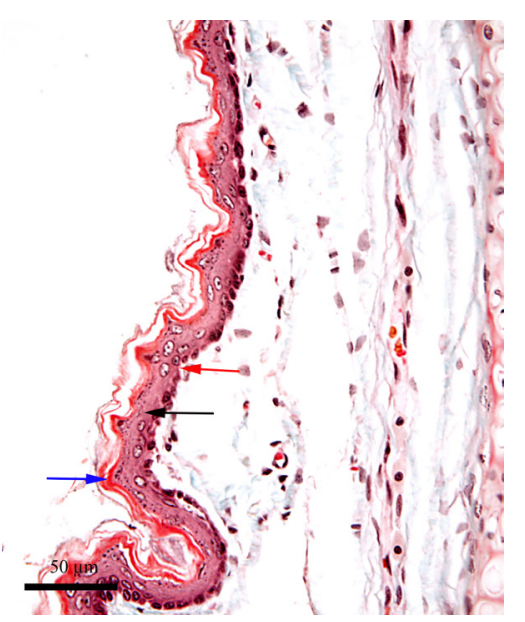

Fig. 1 Epithelium lining the pharyngeal side, Goldner's trichrome stain

red arrow - basement membrane; black arrow keratinized stratified squamous epithelium; blue arrow - keratin 


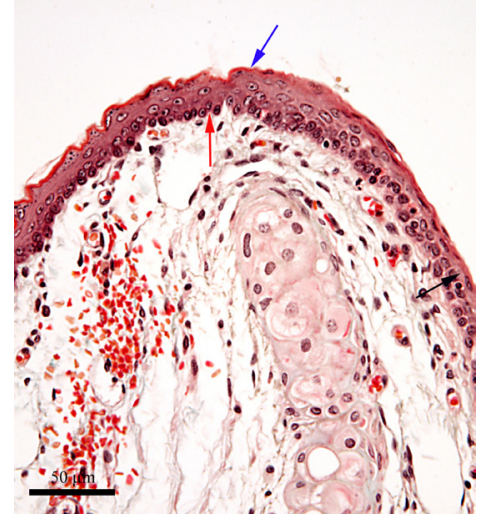

Fig. 2 Apex of the epiglottis, Goldner's trichrome stain red arrow - basement membrane; black arrow nonkeratinized stratified squamous epithelium; blue arrow - keratin

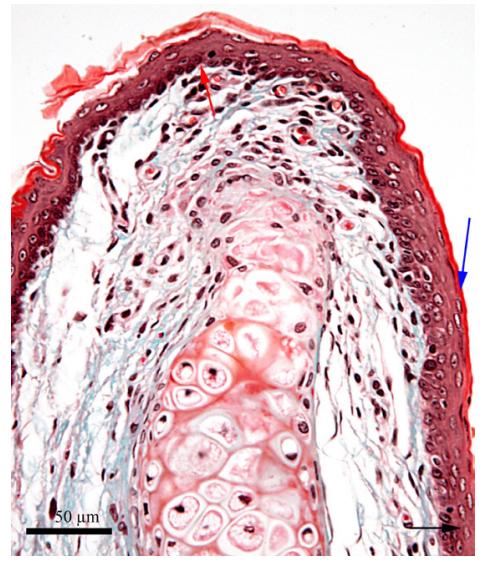

Fig. 3 Apex of the epiglottis, Goldner's trichrome stain red arrow - basement membrane; black arrow nonkeratinized squamous stratified epithelium; blue arrow - keratin

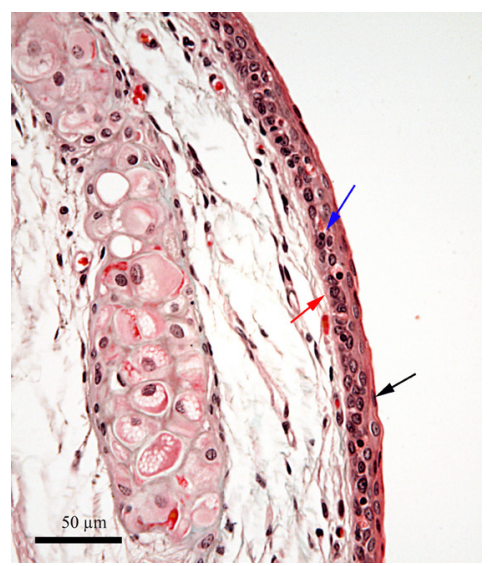

Fig. 4 Apical third of the laryngeal side of the epiglottis, Goldner's trichrome stain

red arrow - basement membrane; black arrow squamous cells; blue arrow - nonkeratinized stratified squamous epithelium

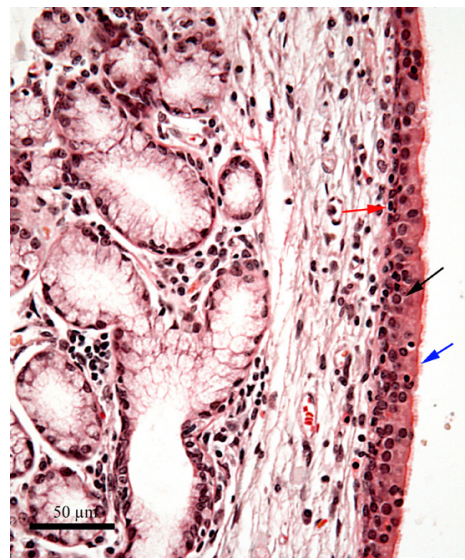

Fig. 5 Basal third of the laryngeal side of the epiglottis, Goldner's trichrome stain

red arrow - basement membrane; black arrow respiratory type epithelium; blue arrow - cilia

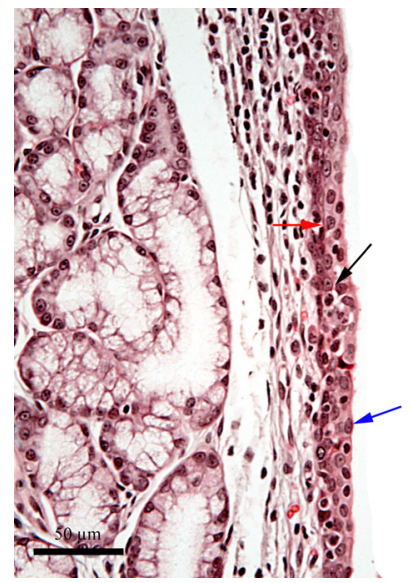

Fig. 6 Basal third of the laryngeal side of the epiglottis, Goldner's trichrome stain

red arrow - basement membrane; black arrow nonkeratinized stratified squamous epithelium; blue arrow - squamous cells

\section{Conclusions}

In Wistar rats, the pharyngeal side of the epiglottis is lined by a keratinized stratified squamous epithelium. The thickness of the keratin layer is not the same in all subjects taken into study. Generally it reaches the apex of the epiglottis and in some cases it extends toward the apical third of the laryngeal side of the epiglottis.

The epithelium which lines the apical third of the laryngeal side of the epiglottis is nonkeratinized stratified squamous epithelium and on the basal half of this side, the epithelium is ciliated pseudostratified columnar. Between these sides, there is a transitional epithelium with few ciliated cells. 
In one rat, the entire laryngeal side of the epiglottis in lined by a non-keratinized stratified squamous epithelium.

Acknowledgments. This research did not receive any specific grant from funding agencies in the public, commercial, or not-for-profit sectors.

\section{References}

1. Gal AF, Miclăuș V (2013). Histology. Cluj-Napoca: Risoprint Publishing House.

2. Hayes AW (2008). Principles and methods of toxicology. (5th ed.). New York: Informa Healthcare, (Chapter 28, pp.1410).

3. Junqueira LC, Carneiro J, Kelly RO (2013). Basic Histology. Norwalk, Connecticut: Appleton\&Lange.

4. Kahwa CKB, Purton M (1996). Histological and histochemical study of epithelial lining of the respiratory tract in adult goats. Small Ruminant Research, 20: 181186.

5. Lewis DJ (1991). Morphological assessment of pathological changes within the rat larynx. Toxicol Pathol, 19: 352-357.

6. Nakano T, Muto H (1987). The transitional zone in the epithelium lining the mouse epiglottis. Acta Anat (Basel), 130: 285-290.
7. Raica M, Mederle O, Căruntu ID, Pintea A, Chindris AM (2004). Histologie teoretică și practică. Timisoara: Editura Brumar.

8. Renne RA, Miller RA (1996). Microscopic anatomy of toxicologically important regions of the larynx of the rat, mouse and hamster. In T. C. Jones, D. L. Dungworth, \& U. Mohr (Eds.), Monographs on pathology of laboratory animals (pp. 44-51). Berlin, Heidelberg: Springer.

9. Renne RA, Gideon KM, Miller RA, Mellick PW, Grumbein SL (1992). Histologic methods and interspecies variations in the laryngeal histology of F344/N rats and B6C3F1 mice. Toxicol Pathol, 20: 44-51.

10. Rus V, Ruxanda F, Matosz B, Rațiu C, Gal A, Miclăuș V (2016). Structural particularities of the epithelium lining the lamb epiglottis. Bulletin USAMV Veterinary Medicine, 73: 445-446.

11. Sagartz JW, Madarasz AJ, Forsell MA, Burger GT, Ayres PH, Coggins CR (1992). Histological sectioning of the rodent larynx for inhalation toxicity testing. Toxicol Pathol, 20: 118-121.

12. Sahota PS, Popp JA, Hardisty JF (2013). Toxicologic Pathology: Nonclinical Safety Assessment. Boca Raton, London, New York: CRC Press, Taylor \& Francis Group, (Chapter 11, pp.383).

13. Smith G (1977). Structure of the normal rat larynx. Laboratory Animals, 11: 223-228. 